\title{
FRACTURAS SOCIALES Y CLAROSCUROS IDEOLÓGICOS: COSTA RICA EN EL SEGUNDO GOBIERNO DE ACCIÓN CIUDADANA
}

\section{SOCIAL FRACTURES AND IDEOLOGICAL CHIAROSCURO: COSTA RICA IN THE SECOND GOVERNMENT OF ACCIÓN CIUDADANA}

\author{
Abelardo Morales Gamboa \\ abelardo.morales.gamboa@una.cr \\ Universidad Nacional, Costa Rica
}

Recibido: 30 de junio de 2018 - Aceptado: 10 de agosto 2018 • Publicado: 9 de octubre 2018

\begin{abstract}
Resumen
El inicio del segundo mandato del Partido Acción Ciudadana, en el gobierno de Costa Rica, está precedido por significativos cambios. En este artículo nos aproximaremos a tres aspectos: primero, los efectos, sobre la sociedad, de la interrelación entre la economía local y la transnacionalización de los capitales; segundo, los vacíos asociado a la crisis del pensamiento ideológico y la continuidad del conservadurismo; y, finalmente, la declinación del papel estabilizador de las capas medias en lo social y en lo político. En esa correlación de factores, se analiza el debilitamiento de la sociedad civil y las fracturas sociales, políticas, culturales y territoriales que fraccionan a Costa Rica en sociedades muy desiguales. El trasfondo de estos reacomodos no es solo económico y político sino ideológico; se afianza el neoliberalismo como complejo de doctrinas que guían la lógica económica, pero también la adhesión de esas creaciones a elaboraciones ideológicas que condicionan las sensibilidades colectivas (deterioro de la cohesión social, desafección con las instituciones y reencantamiento mesiánico de las masas).
\end{abstract}

Palabras clave: Costa Rica, partidos políticos, estructura social, ideología, control social

\begin{abstract}
The start of the Acción Ciudadana Party's second term, in the government of Costa Rica, is preceded by significant changes. In this article, we will approach three aspects: first, the effects, on society, of the interrelation between the local economy and the transnationalization of capital; second, the gaps associated with the crisis of ideological thought and the continuity of conservatism; and, finally, the decline of the stabilizing role of the middle strata, both socially and politically. In this correlation of factors, we analyze the weakening of
\end{abstract}


civil society and the social, political, cultural and territorial fractures that divide Costa Rica into very unequal societies. The background of these rearrangements is not only economic and political but ideological; neoliberalism is strengthened as a complex of doctrines that guide economic logic, but also the adhesion of these creations to ideological elaborations that condition collective sensibilities (deterioration of social cohesion, disaffection with institutions and messianic reenchantment of the masses).

Keywords: Costa Rica, political parties, social structure, ideology, social control

La coyuntura marcada en Costa Rica por el inicio del segundo mandato consecutivo del Partido Acción Ciudadana (PAC) ha sido precedida por una colada histórica que, para no explorar en su arqueología, y por la dificultad de precisar sus dimensiones particulares ahora, diríamos que data de al menos tres decenios atrás. En su explicación, intentaremos tres posibles entradas: la primera de ellas, el des-re-dibujamiento de la sociedad costarricense en el contexto de una economía transnacionalizada; la segunda, el vacío político asociado a la crisis del pensamiento ideológico y la continuidad del conservadurismo; y, finalmente, la declinación del papel estabilizador de las capas medias en lo social y en lo político. Lo que se produce es un debilitamiento de la sociedad civil porque se erosionó profundamente la confianza, tanto en los partidos políticos como en la cultura cívica, así como en las instituciones y en otros espacios públicos; dicha entidad está experimentando fracturas sociales, políticas, culturales y territoriales que fraccionan a Costa Rica en nuevas esferas de la desigualdad. El trasfondo de estos reacomodos no descansa únicamente en lo económico o lo político, también tiene una base ideológica que busca afianzar el neoliberalismo en tanto doctrinas que se adhieren al pensamiento como por las formas que condicionan las sensibilidades (deterioro de la cohesión social, desafección con las instituciones y reencantamiento mesiánico de las masas).

\section{La sociedad se redibuja sobre claroscuros relieves}

La sociedad costarricense transita por un momento particular de su historia. Este es un momento de radicales cambios, sobre todo en las principales tendencias de su desarrollo económico, pero con expresiones en diversas esferas de lo social, lo cultural y lo simbólico. Una década atrás, con la aprobación en referéndum, en el 2007, del Tratado de Libre Comercio con 
Estados Unidos (CAFTA) ${ }^{1}$, se terminó de imponer un modelo económico que apostaba por la apertura comercial, la atracción de inversiones, la ley de mercado en la administración de servicios como la telefonía, la electricidad y los seguros; además del abaratamiento de la mano de obra. Poco después la crisis internacional de 2008 desnudaba los límites de ese modelo y sus efectos inmediatos se hicieron sentir en las actividades económicas más conectadas con el exterior como el turismo y las exportaciones agrícolas e industriales, pero también evidenciaron claras repercusiones sobre los modos de vida social y de consumo que se comenzaban a organizar en torno a las nuevas estrategias transnacionales (Robinson, 2017).

Pese a las expectativas de cambio social que se alentaron desde la transición de gobierno en el 2014 (Rosales, 2015) hasta la actualidad, los desajustes y fracturas originadas por la economía transnacional y la desigualdad social han persistido, sin que sobre ella se hubiera propuesto cambios importantes en los programas políticos de ambas administraciones, ni en las propuestas de los partidos y fuerzas políticas de oposición al pacto hegemónico. El resultado ha sido la continuidad de un transnacionalismo administrado y la modelación de un escenario político que transita entre el progresismo y el conservadurismo.

Según se señalaba en un reporte del Banco Mundial de 2014, "Costa Rica ha registrado una expansión económica estable en los últimos 25 años, debido, principalmente, a la implementación desde finales de la década de los 80 de una estrategia orientada hacia el exterior, un crecimiento liderado por las exportaciones, la apertura a la inversión extranjera y una gradual liberalización del comercio". 2 Pero esto contrastaba con el notable crecimiento de la desigualdad social, lo que ha significado una contradicción con las promesas de los actores políticos impulsores del nuevo pacto transnacional, pues este ha propiciado mayor concentración de la riqueza (PNUD, 2017).

Por ello, el primer triunfo electoral, en abril de 2014, del Partido Acción Ciudadana y de su candidato Luis Guillermo Solís Rivera, despertó enormes expectativas, en gran parte de los electores, sobre los posibles

1 El CAFTA, siglas con las cuales se conoce el citado Tratado, fue suscrito en el año 2004, enviado a referéndum en el año 2007, año en el cual fue ratificado y entró en vigencia el 1. de enero del 2009. Desde su formulación se han presentado argumentos a favor y en contra de los efectos de dicho acuerdo (Xirinachs, 2017).

2 Información recuperada de: http://www.bancomundial.org/es/country/costarica/overview el 29/11/14, a las 18:39. 
cambios en la situación del empleo y de la desigualdad social. Las esperanzas albergadas por la población, en especial, los grupos de bajos ingresos y de sectores medios en riesgo de una movilidad social descendente, se alimentaron de las críticas que planteaba ese partido a los orígenes del deterioro social, de la corrupción y a las malas gestiones de los últimos gobiernos. No obstante, el gobierno del PAC se encontraba en una situación de debilidad dentro de una correlación de fuerzas dominadas por los pactos con el neoliberalismo y el conservadurismo de otras formaciones políticas, así como de las tempranas ambigüedades y contradicciones de la bancada de izquierda -representada por el Frente Amplio- y de la misma bancada oficialista. Esas contradicciones no solo no se resolvieron en el segundo mandato de ese partido, sino que se han profundizado y generaron nuevas rupturas políticas, principalmente con las formaciones sindicales y otras organizaciones sociales, en torno a una temprana propuesta de reforma fiscal. Para hacer posible su triunfo en segunda ronda, en 2018, el PAC formó una alianza con el candidato del Partido Unidad Socialcristiana y como principal cuota política, este grupo colocó en puestos estratégicos de la gestión económica a tecnócratas más alineados al conservadurismo económico y a la abstinencia del gasto público.

Las reformas económicas iniciadas en los años noventa y su giro transnacional a partir de la entrada en vigencia del CAFTA en el 2009 no revirtieron el crecimiento de la desigualdad social. El informe del Proyecto Estado de la Nación, producido por las universidades públicas del país, a través de un estudio de las tendencias de mediano plazo mostraba que, pese a los avances en otros campos, en Costa Rica se producía un claro rezago en la distribución de la riqueza:

Es claro, entonces, que los beneficios del crecimiento económico experimentado desde 1994 no han sido compartidos por toda la sociedad costarricense. En consecuencia, en 2013 la desigualdad en la distribución de los ingresos era casi un 40\% superior a la que prevalecía en 1990 y mayor al promedio latinoamericano, una situación inversa a la existente en 1990... Mientras que aquí aumentaba la desigualdad (y alcanzaba sus máximos niveles históricos), en el resto de América Latina disminuía. (Programa Estado de la Nación, 2014, pág. 289) 
Entre otros factores asociados a ese crecimiento de la desigualdad, se pueden identificar procesos crecientes de concentración de ingresos por parte de los grupos que se encuentran en la cima de la pirámide social, especialmente de los estamentos sociales vinculados a los negocios transnacionales y a la acumulación global, versus un acelerado deterioro de las condiciones de trabajo para los sectores de ingresos medios y bajos, y la pérdida de capacidad del Estado para mantener las tradicionales estrategias de transacción social entre los sectores del capital y los del trabajo y para asegurar vías de movilidad social. El dispendioso gasto de los presupuestos públicos que se practicó a partir de 2006 contrastaba con una estructura tributaria poco sostenible en el mediano plazo; además que otros sistemas que dependían del presupuesto estatal, como transferencias financieras a diversas instituciones, regímenes de pensiones y garantías salariales negociadas con los sindicatos, absorbían buena parte de los recursos financieros.

Las políticas para contener la pobreza estuvieron basadas, casi exclusivamente, en los programas para transferir fondos públicos a las familias pobres, mediante la entrega de bonos para construir viviendas, becas escolares y otros instrumentos de asignaciones comunitarias y familiares; estos contribuyeron a mantener a muchos grupos a flote de la pobreza extrema, pero no resolvieron la desigualdad ni procuraron medios para promover el bienestar y ascenso social de los grupos de menos ingresos.

El empleo dejó de ser un mecanismo para procurar bienestar social a los costarricenses. Un año antes del inicio del primer gobierno del PAC en 2013, en el informe Coyuntura laboral en América Latina y el Caribe de la Comisión Económica para América Latina (CEPAL) y de la Organización Internacional del Trabajo (OIT) Costa Rica figuraba en la lista de países con una mala calificación de la dinámica del empleo debido al crecimiento del subempleo por el aumento del porcentaje de personas que trabajaban menos de la jornada laboral y no obtenían los ingresos salariales suficientes para vivir (Naciones Unidas, CEPAL, OIT, 2013).

Pero los problemas del empleo tenían y mantienen dimensiones estructurales. Mientras en el país se produjo un crecimiento de inversiones y negocios, tanto la cantidad como la calidad de los empleos no absorbieron la oferta de fuerza de trabajo en diversos segmentos del mercado laboral. El crecimiento benefició a algunos segmentos de mano de obra calificada, pero 
debido al estancamiento de la educación secundaria, esto resultó inefectivo para resolver la exclusión de las personas jóvenes del mercado laboral, inclusive de jóvenes graduados de profesiones universitarias. El tipo de inversiones atraídas por el nuevo modelo, ahora menos aún, no proporcionaba una salida a los problemas de empleo de los trabajadores menos calificados. En el periodo comprendido entre el tercer trimestre del 2010 y el segundo del 2011, o sea dos años después de la entrada en vigencia del CAFTA, el mercado laboral costarricense había perdido 128612 empleos (Segura, 2013). Mientras tanto, uno de los problemas que más destacaban como expresión del debilitamiento del mercado de trabajo eran el desempleo juvenil y el débil efecto de la educación formal para asegurar la inserción en el mercado de trabajo de las personas jóvenes (Naciones Unidas, CEPAL, OIT, 2017).

Pese a una leve recuperación, que ocurrió en 2013, el estancamiento del empleo se mantuvo constante a partir de 2014; esto debido a varias razones. En primer lugar, la dinámica del empleo ha continuado subordinada a un lento ritmo de crecimiento de la economía, no ha habido mejoras reales en el empleo formal, sino al aumento del trabajo por cuenta propia y, además, mitigada por el aumento del subempleo y sus efectos negativos en la zona rural y entre las mujeres trabajadoras (Naciones Unidas, CEPAL, OIT, 2017). No hubo progresos sustantivos en el cumplimiento del pago del salario mínimo por parte de los empleadores. El efecto de la crisis de 2008 se tradujo en el despido de varios miles de trabajadores por parte de empresas que trasladaron sus plantas a otros países alegando altos costos de producción, entre ellos los de la mano de obra. Los trabajadores cesantes debido al cierre de empresas pertenecían a diversos sectores, pero se le había dado mayor difusión a los despidos en la industria, agroindustria, hotelería, comercio y restaurantes durante el bienio 2014-2015, que fue el periodo más intenso de la crisis de empleo, inclusive en el ramo de los medios de comunicación, pero en el periodo posterior no se ha producido la reincorporación de estos segmentos de trabajadores y trabajadoras a empleos formales y ello ha dado como resultado la aparición de variadas formas de ocupación en la informalidad, tales como los servicios de transporte privado informales, como los servicios de "Uber", y un aumento del cuentapropismo entre sectores de ingresos bajos y medios. 


\section{... y las desigualdades reemergen bajo las sombras neoliberales}

Los fenómenos políticos recientes, en especial los dos últimos resultados electorales, más que una voluntad política de cambio racional, pueden expresar el producto de vaciamientos políticos y reacomodos que estos mismos, así como la crisis y la desigualdad, provocan en el comportamiento de actores sociales, colectivos e individuales. El antiguo proyecto hegemónico para nada ha sido puesto en cuestión y más bien se ha restituido con nuevos refuerzos ideológicos. Pese a los cambios de escena política, las nuevas formas de la dominación se fusionan con las variaciones de la economía transnacional que le suministra un nuevo tejido de soportes y alianzas a viejos grupos dominantes y antiguas oligarquías. De allí la presión constante sobre la necesidad de un Estado pequeño pero eficiente, que dirija recursos y energías para apoyar las nuevas formaciones económicas. Como resultado germina una nueva configuración de fuerzas en torno a las fuentes transnacionales que empujan de manera constante sobre la desnacionalización de los negocios y de las fuentes estratégicas de acumulación de riqueza. En ese escenario destaca una fracción político-económica que se ha aliado a las corporaciones transnacionales en torno a los negocios bancarios, el turismo, la inversión inmobiliaria, las agroexportaciones, servicios de outsourcing, los medios masivos, industria publicitaria y redes sociales, cuya arquitectura es estratégica en el ensamblaje de nuevos controles ideológicos sobre la sociedad, principalmente con la cooptación de los grupos medios educados a partir del círculo vicioso del crédito y el consumo. La racionalidad instrumental del neoliberalismo apuesta fuertemente por la formación de una tecnocracia funcional a las necesidades de mano de mano de obra especializada, por ello se le exige al Estado mayor inversión en ciencias y tecnología, aunque los cuadros profesionales que de allí surjan deban competir en mercados cada vez más precarizados.

Tales fuerzas articuladas alrededor del pacto social neoliberal y transnacional, en el desarrollo económico, político y social del país, lograron imponer su poder y desplazar las alternativas de cambio, ya fueran estas como continuidad de la modernización reformista o del romanticismo progresista inspirado en los movimientos sociales del 2000 en adelante. Los movimientos sociales de resistencia al neoliberalismo experimentaron su principal derrota 
estratégica debido a la dispersión tanto social, como política e ideológica de sus bases de grupos medios. Esa hegemonía incontestada por los bajos niveles de resistencia social y, prácticamente, por la aceptación cultural de los patrones de vida transnacional, principalmente la subordinación al consumo, por parte de las clases medias y populares, ha engendrado una nueva sensibilidad de la mano de la dominación cultural. Las acciones del gobierno desde el 2014, lejos de abrir nuevas avenidas para el cambio social, retomaron la estrategia de administrar un programa de políticas neoliberales (transnacionalismo administrado) desde el Gobierno. Ello debido a la adversa correlación de fuerzas de Acción Ciudadana que ganó la Presidencia en el primer periodo (2014-2018) pero estuvo en minoría en el Congreso; mientras en el segundo (2018-2022), ganó la presidencia pero cedió al PUSC cargos estratégicos en el Poder Ejecutivo y se profundizó aún más su debilidad parlamentaria al perder varios diputados en las elecciones.

La débil resistencia social tiene también explicación, por su parte, en la dispersión social y política y en la heterogénea composición de segmentos de la sociedad costarricense en ese nuevo contexto global. Las transformaciones demográficas, el acceso a beneficios derivados de las políticas públicas -principalmente en salud y educación- y de ascenso social, propiciaron la ampliación y la apertura de brechas debido a las desigualdades y marginación que han experimentado vastos grupos sociales de las oportunidades del pacto neoliberal, ello debido a desventajas sexuales y de género, étnicas y etarias; a una división centro-periferia que estableció nuevas fronteras territoriales sobre la calidad de vida, y ya no solo entre el campo y la ciudad sino al interior de esos mismos escenarios, en el acceso al empleo y a los derechos relacionados con la ciudadanía. Para los marginados, su integración al pacto transnacional se ha reducido a poder disponer de ocupaciones e ingresos; todas las demás conquistas sociales de bienestar serían simples concesiones del sistema, por medio de subsidios y transferencias para los grupos que se encuentran en exclusión extrema.

Mientras tanto, las fuerzas de oposición al pacto hegemónico continuaron orientando sus acciones políticas bajo el ideario de una sociedad que se había quedado en el pasado y quizás sin ofrecer a los costarricenses una nueva sociedad o propuestas de esperanza frente las desigualdades y la transnacionalización. Los movimientos sociales que adquirieron recientes 
expresiones se reconfiguraron en torno a luchas, demandas y expresiones de movilización política nuevas, pero las agendas o reivindicaciones emergentes relacionadas con los derechos humanos, la inclusión social o sexual, no permitieron tampoco, sino que en ocasiones dificultaron, la formación de alianzas al interior de las fuerzas más desarrolladas, pues algunas de ellas han entrado en contradicción con profesiones de la fe o ideas morales de sus bases o sus mismas dirigencias, e ideológicamente esas luchas pueden moverse entre progresismo o conservadurismo.

En otra vertiente, es cada vez más palpable el protagonismo de los sectores medios en la reconfiguración de la sociedad costarricense. Las contradicciones entre las élites que concentran mayor poder y riqueza y las masas excluidas, se ven opacadas por los argumentos conflictos y ambigüedades que plantea la difusión cultural de las pautas de consumo, los modos de vida y la inmediatez de las demandas sociales de dichos sectores que están teniendo impacto en las cada vez más insatisfechas aspiraciones de las capas medias. Si para las personas más pobres las ocupaciones e ingresos constituyen su fuente vital, para los segmentos medios ello se trasciende, pues consideran más importante poder satisfacer, además, las expectativas de consumo y por esa vía el ascenso social. Congestionadas o interrumpidas las vías para atender las necesidades de la sobrevivencia social o las expectativas del consumo, la acción de los grupos populares y estratos medios no se ha orientado a la reconstrucción de las formas autónomas de acción política, sino que estas se han venido subordinando a los poderes mágicos del encantamiento mesiánico de los partidos religiosos y las fracciones ultraconservadoras que, además del avivamiento de autoritarismos latentes, reproducen, constantemente, la representación de una sociedad amenazada por migrantes, criminales y políticos corruptos.

\section{La opacidad de las ideologías políticas en el siglo XXI}

Sería erróneo atribuir esos procesos, anteriormente señalados, solamente como resultado de las dinámicas estructurales, sobre todo de base económica, o inclusive reducirlos a comportamientos individuales de fuerzas o de los actores políticos, y no reflexionar sobre las relaciones de esas fracturas con las vertientes del pensamiento político y su reemplazo por nuevos imaginarios. 
En ese escenario, el lente más opaco para mirar hoy en día a través suyo el resto de la sociedad es quizás el de las ideologías, pero de aquellas elaboraciones racionales, conscientes y colectivas, que bajo propósitos políticos, formales y específicos dividieron el mundo entre las esferas del conservadurismo, el liberalismo burgués, la izquierda revolucionaria o reformista y luego la socialdemocracia, el socialcristianismo y el centrismo. Aunque el mundo no se puede mirar fuera de ellas, pues la mirada siempre está mediada por ideas y representaciones del mundo, las formas ideológicas se van reemplazando con cada cambio en el desarrollo histórico. Con la Ilustración, las ideologías reemplazaron a la religión para proyectar un destino terrenal sobre la sociedad. Por ello, las ideologías, y no todas las formas subjetivas de mirar el mundo que las antecedieron, fueron heredadas por la modernidad burguesa, cuando permitieron separar los espacios de lo sagrado y lo profano e hicieron posible el desarrollo del pensamiento secular para dotarlo de herramientas para la acción y, también, con ellas aparecieron los movimientos sociales (Wallerstein, 2004).

La declinación de las ideologías había sido inicialmente discutida por Bell (Bell, 2015) cuando anunciaba el agotamiento de las ideas políticas decimonónicas y su reemplazo por el pragmatismo. Con el mismo sesgo optimista y globalista, Fukuyama vaticinaba, a inicios de los noventa, el triunfo del conservadurismo liberal sobre las doctrinas que promulgaban el cambio social. Pero en realidad, hoy día podríamos señalar que el declive de las doctrinas ideológicas también sacude a ese liberalismo ficticiamente triunfante que, sin desaparecer, en diversos lugares del mundo le cedió terreno a otros ensamblajes ideológicos invadidos de conservadurismo, populismo, mesianismo y, más recientemente, del reencantamiento religioso de la vida social. Nada nuevo, de todas maneras, en la historia del liberalismo desde el siglo XIX.

Una sociedad como la costarricense, que con frecuencia ha guardado un apego real o ficticio a esos repertorios políticos muestra, a partir de sus transformaciones, una creciente des-re-vinculación entre procesos sociales, acciones colectivas y lealtades ideológicas derivadas de las doctrinas partidarias. Pero tales transacciones imaginarias no son extrañas pues, como señalara Solís (Solis, 1992), en esta sociedad aquellos idearios se han resguardado en la apariencia de métodos del pensamiento político que han transitado entre un paradigma reformista y otro conservador. 
Como señala este mismo autor, después de 1948:

el PLN transforma a Costa Rica, le da otra fisonomía; en esta labor tiene como punto de referencia tesis y valores de los socialdemócratas de los años cuarenta. El problema, por lo tanto, es identificar esa matriz que, sin ser idéntica a los planteamientos posteriores del PLN, ha hecho posible su paso de un reformismo estatista a un neoliberalismo administrado, sin tropezar con grandes resistencias ni cortes abruptos en esa transformación (Solis, 1992, pág. 81).

No obstante, los vacíos que dejó esa formación política no fueron poca cosa y solo coyunturalmente pudieron ser ocupados por varios intentos, tanto dentro como externamente al partido, de restauración reformista, de defensa del Estado de bienestar y re-invocación a aquella aspiración socialdemócrata.

En el caso del PLN, eso fue así al menos hasta finales de los años ochenta, cuando el progresismo reformista mantuvo un espacio deliberante dentro de las estructuras del partido. A partir de mediados de los noventa y a lo largo de los dos decenios subsiguientes las divisiones, fraccionamientos y desvanecimiento del partido fueron más que evidentes. Por el contrario, el colapso de la oposición tradicional al PLN, el Partido Unidad Socialcristiana, estuvo menos relacionado con su debacle ideológica puesto que las tesis del neoliberalismo económico nunca le llegaron a plantear ningún desafío ético ni ideológico a esa narrativa socialcristiana. Más bien por el contrario, la crisis de este partido fue precipitada por la corrupción de sus líderes más prominentes y sus vacíos fueron rellenados con poco éxito por una versión del liberalismo decimonónico tanto adentro como afuera -el Movimiento Libertario- con un programa conservador de defensa del modelo de acumulación transnacional y el desmantelamiento institucional fue la continuidad a su tradicional oposición al reformismo liberal. La izquierda que nunca ha sido una opción política verdaderamente contestataria, por su parte, tuvo una pronunciada erosión a partir de finales de los setenta cuando se iniciaron múltiples divisiones en sus formaciones políticas, hasta el punto de que estas se fueron desconectando de sus bases obreras y las fueron reemplazando con una militancia predominantemente de grupos medios -principalmente intelectuales, burócratas y otros trabajadores estatales-, para finalmente arrastrar por décadas los efectos de la crisis del marxismo internacional. 
En el contexto de los movimientos sociales de 2000 en adelante, las luchas populares contra los intentos de privatizar la electricidad y las telecomunicaciones, contra el tratado de libre comercio y otras luchas sociales nacionales y locales, se comenzó a rearticular una formación de izquierdas en torno al Frente Amplio que tuvo un ascenso meteórico en el 2014 cuando logró llevar 9 diputados al congreso de la República pero experimentó un fuerte repliegue en las elecciones de 2018, cuando su formación volvió a quedar reducida a 1 diputado.

Tanto el Partido Liberación Nacional (PLN) como partido hegemónico en el periodo iniciado en 1948, como sus tradicionales grupos de oposición liberal conservadora, lo mismo que los partidos de izquierda, comenzaron a padecer una pronunciada crisis ideológica y programática. Los vacíos que ella provocó hicieron posible diversos intentos de recomposición reformista a finales del siglo anterior, cuya expresión más acabadamente imperfecta terminó siendo el mismo Acción Ciudadana, constituido como una mixtura de cuadros, no de fuerzas visibles, que antes figuraron en el alero socialdemócrata del PLN o en progresismo socialcristiano; además de grupos y exdirigentes de la vieja izquierda marxista y de algunos movimientos sociales y religiosos. Si bien el PAC resumió el activismo político de importantes movimientos sociales como la defensa de instituciones públicas en el 2000 y la lucha contra el Tratado de Libre Comercio entre 2006 y 2007, entre otros, su función latentemente conservadora fue la de contener el crecimiento de la movilización sociopolítica para impedir su transmutación hacia una apuesta política de transformación social. Tanto el PAC convertido en formación parlamentaria como en gobierno no solo opacó sino que cooptó la movilización sociopolítica que le diera origen.

Por eso, los dos triunfos consecutivos del Partido Acción Ciudadana (PAC), primero en las elecciones de 2014 y luego en las de 2018, y los resultados que eso ha producido en la dinámica del gobierno y en las esferas de la política, han dejado al descubierto esas transmutaciones ideológicas que surgidas de la modernidad precedieron a otras que redibujaron a una sociedad costarricense sometida a las presiones de la globalización económica y de sus derivaciones culturales y políticas. Tanto las condiciones que catapultaron al Partido Acción Ciudadana como segunda fuerza electoral durante los dos periodos previos antes de llegar al gobierno, como su misma 
conformación como fenómeno político, ejemplifican esa metamorfosis de dispositivos ideológicos, entre progresismo y conservadurismo, en la sociedad costarricense. La base de ese proyecto electoral que ha sido el PAC tiene también relación con la situación de los sectores medios que han sido su principal base social.

\section{Las clases medias entrampadas en el país más feliz del mundo}

Las clases medias, emblema del igualitarismo social de Costa Rica, parecen deslizarse por el piso jabonoso de la inestabilidad hacia un descontento político sin rumbo. El ocaso de las clases medias no significa su desaparición; por el contrario, su tamaño creció de menos de 20 \% a más del 40 \% durante los últimos tres decenios (Programa Estado de la Nación, 2009); pero sí la de su papel estabilizador en el sistema social y político, en el de antes cuando los empleos y políticas de la modernización tercermundista hicieron que de hogares pobres, de la clase obrera y del campesinado, sugieran hombres y mujeres profesionales, oficinistas, empleados de servicios y obreros calificados, muchos de la mano del empleo público. Pero ahora, ese conjunto social es cada vez menos igualitario, sus miembros se decantan por el consumo, el individualismo y, sin proyectos que los ilusione, por las salidas de corto plazo.

En el siglo anterior, el Estado desarrolló infraestructuras que dieron a los costarricenses empleos, educación y salud pública, redes de protección, garantías laborales e impulsaron la movilidad social. Al compartir hábitos de consumo y convivir en espacios residenciales y de recreación, escuelas, clínicas y otros lugares públicos, con otros estratos más bajos de la pirámide social, esas clases medias, relativamente educadas, reprodujeron valores y prácticas de solidaridad. Además de cierto arraigo popular, ellas también compartían con sus ancestros proyectos personales y familiares, como poseer vivienda propia antes de tener auto, educar a los hijos antes de viajar y ascender laboralmente antes de endeudarse en consumo suntuario. Todo era posible bajo un proyecto de país y un régimen estatal que desarrollara políticas de inclusión social.

Los campesinos y obreros desposeídos encontraron atajos institucionales que respondieron a sus necesidades y demandas. Por eso, los sectores 
medios no estuvieron atrapados en la bisagra entre ricos y pobres y no tuvieron la necesidad de definirse ideológicamente entre la izquierda y la derecha, ellos fueron los beneficiarios del progresismo conservador y del distribucionismo. En 24 años, los grupos medios se transformaron tanto cuantitativa como cualitativamente. Mientras que en 1992 representaban menos de una quinta parte, diez años después ya eran casi un tercio de la población; desde 2009 se duplicaron y ahora sobrepasan el 40 \%. Aun siendo su representación hasta antes de 1990 menor al 20 \%, su participación sociopolítica fue clave en el establecimiento de las formas de convivencia que dieron estabilidad política al país. Tras el cambio del modelo productivo y de las estrategias de acumulación, así como la absorción de la burguesía nacional por una élite transnacional, se redefinió el lugar de las clases medias.

La feminización y la movilidad del empleo, las oportunidades de educación superior y el incremento de los ingresos, permitieron el ensanchamiento de la franja que colocó a Costa Rica como el cuarto país de América Latina con el mayor porcentaje de clases medias. Ese aumento, según las viejas teorías del desarrollo, podría tener efectos favorables porque su capacidad de demanda podría haber incentivado la productividad y el empleo. Pero eso no resultó cierto; solo un pequeño segmento del capital ha sacado provecho de esa expansión del consumo. El desplanificado y nada sostenible crecimiento de la inversión inmobiliaria residencial y comercial, el desproporcionado parque de automóviles, la proliferación de tarjetas de crédito y de modalidades de endeudamiento, los paquetes turísticos, la industria del espectáculo y hasta carreras universitarias afines al mercado, se alimentan del consumo de las clases medias. Pero lo que es bueno para el mercado no siempre lo es para el resto de la sociedad.

A falta de otras estrategias sociales, el mercado acaba moldeando gustos y comportamientos. Mediante variadas estrategias bancarias, el mercado financiero ha popularizado la idea de que las deudas no son motivo de vergüenza ni privativas de quienes solo tienen un ingreso bajo, sino una característica de la inteligencia financiera.

$\mathrm{Al}$ incremento demográfico y el de los ingresos y gustos, le acompaña un cambio de las actitudes culturales y comportamientos políticos de dichas clases. Crece el número de individuos que en su vehículo privado no caben en las estrechas vías públicas; el empleo público, el formal y el trabajo 
estable se acabaron pues la educación e, inclusive, la formación profesional, han dejado de ser una oportunidad para tener un empleo formal y estable y para el ascenso social. Los límites de endeudamiento en muchos casos se mantienen por encima de la capacidad de pago; aumenta el descontento por la mala calidad de los servicios públicos y hasta por las aglomeraciones en los centros comerciales. La adquisición de una vivienda propia, en un residencial seguro y exclusivo, obliga a endeudarse casi de por vida sin tener seguridad en el empleo.

No parece haber mucho futuro para los postulados optimistas que aún asignan a estos estamentos un papel estabilizador frente al conflicto social y de moderación ideológica ante la polarización política. Unos sectores compiten y se enfrentan a otros grupos medios y a otros segmentos sociales por las escasas oportunidades de educación, empleo y acceso a servicios públicos y con ello, se acaba la solidaridad y el sentido de colectividad. Tensiones y contradicciones van estrechando los espacios de coexistencia, producen un arrollador desencanto, elevan el estrés colectivo, la intolerancia y la agresividad cotidiana en niveles difícilmente manejables para la salud mental de un país que se complace de ser el más "pura vida”. Una parte importante de los individuos que conforman a estos colectivos comienzan a ser atrapados por las ideas de un fanatismo populista que le exige al Estado que produzca más infraestructura y servicios de calidad, vías más amplias para circular, pero se resiste al pago de más impuestos; que se acabe con la inseguridad pero convierten las carreteras en teatro de guerra; que pague menos a los funcionarios públicos, que no financie las universidades, que detenga el ingreso de más extranjeros, que el Estado se haga más pequeño pero que vuelva a garantizarles el ascenso social.

Ese panorama se resume en una imagen de la vida cotidiana: largas filas de vehículos, algunos espaciosos y de modelo reciente, ocupados por personas bien vestidas que viajan solas, con formación profesional la mayor parte, detenidos o que circulan a velocidades mínimas por estrechas vías y calles de barrio infestadas de tráfico, son el síndrome de unas clases medias estancadas porque se agotaron las vías que otrora hicieron posible la movilidad no solo espacial sino social. Atrapados en la inmovilidad, presos de las frustraciones y desilusionados de las propuestas políticas vigentes y del estamento político, algunos segmentos de las clases medias comienzan 
paulatinamente a ser vencidos por los discursos mesiánicos y reacciones ultraconservadoras y antidemocráticas. Una reconsideración profunda de las clases medias se impone en este país, pues nunca, ni siquiera en medio de las fuertes tensiones de la crisis política de inicios de los ochenta y de la guerra centroamericana, la viabilidad política de la sociedad costarricense había alcanzado tales límites, la erosión de sus principales bases sociales.

A fin de cuentas, el neoliberalismo y la transnacionalización administrada han venido a poner fin a la adhesión de los sectores medios a una cultura política inclinada por el dar, ceder y recibir, que había facilitado los acuerdos político-sociales y la formación dentro de los mismos de líderes políticos que conservadoramente se adaptaban a ese juego. Inclusive durante los años de declinación del viejo sistema partidario, su tradicional moderación política le cerró caminos a la izquierda radical y al extremismo neoliberal. Pero a su crecimiento, a los grupos medios les ha llegado la hora, bajo el agotamiento de los modos de vida y reglas de la política que le dieron estabilidad a este país. Esa erosión de la estabilidad se traduce en procesos de movilidad descendiente y el riesgo de su caída en la pobreza; además de ello, sus anteriores referentes políticos están cada vez más diluidos en la opacidad y en su lugar, en el del desencanto ideológico, emerge el reencantamiento mágico de las diversas expresiones de mesianismo político religioso con particularidades propias de la sociedad costarricense, pero con similitudes a otros países de América Latina donde también se experimenta una fractura estructural de las capas medias como forma de salvar a los capitales.

Lo que se produjo como resultado de fracturas sociales y el ensombrecimiento del pensamiento político es que la sociedad civil se debilitó porque se erosionó profundamente la confianza no solo en los partidos políticos sino en la cultura cívica, en las instituciones y en otros espacios públicos; esa sociedad civil está experimentando agrietamientos sociales, políticos, culturales y territoriales que fraccionan a Costa Rica en sociedades muy desiguales. Debido a ese debilitamiento de la vida civil, los fetichismos religiosos o el encantamiento mesiánico se han fortalecido y la continuidad del PAC en el gobierno, lejos del cambio, es una señal de continuidad política de un transnacionalismo administrado. Las opciones no parecen claras en lo inmediato pero las batallas que enfrenta esta sociedad no se resolverán con la simple apuesta de relleno de las grietas sociales, pues no solo se han resquebrajado las bases materiales 
de la cohesión social, sino también en el cemento ideológico con grietas no solo en las plataformas de pensamiento político sino en la urdimbre de las subjetividades y sensibilidades individuales y colectivas.

\section{Referencias Bibliográficas}

Bell, D. (2015). El final de las ideologías. Sobre el agotamiento de las ideas políticas en los años cincuenta. Madrid: Alianza Editorial.

Naciones Unidas, CEPAL, OIT. (2013). Coyuntura laboral en América Latina y el Caribe: desafíos e innovaciones de la formación profesional. Santiago: CEPAL.

Naciones Unidas, CEPAL, OIT. (2017). Coyuntura Laboral en América Latina y Caribe. La transición de los jóvenes de la escuela al mercado laboral. Santiago: CEPAL. Obtenido de https://www.ilo.org/wcmsp5/groups/public/---americas/---ro-lima/---sro-santiago/ documents/publication/wcms_584365.pdf

PNUD. (2017). La desigualdad en Costa Rica y el cumplimiento de la Agenda 2030 para el Desarrollo Sostenible. San José: FLACSO y PNUD.

Programa Estado de la Nación. (2009). Decimoquinto Informe Estado de la Nación en Desarrollo Humano Sostenible. San José: Programa Estado de la Nación.

Programa Estado de la Nación. (2014). El desarrollo humano en perspectiva comparada (1994-2013). San José: Programa Estado de la Nación.

Robinson, W. (Noviembre de 2017). ¿La Próxima Crisis Económica? Capitalismo Digital y Estado Policiaco Global,. ALAI. Obtenido de https://www.alainet.org/es/ articulo/189343

Rosales, R. (2015). "Elecciones en Costa Rica 2014: El aparente giro hacia el progresismo de izquierda mediante el triunfo del Partido Acción Ciudadana y el ascenso del Frente Amplio". Anuario CIEP, Universidad de Costa Rica, vol 6: 155-175, 2015, 155-175.

Solís, M. (1992). Costa Rica: ¿Reformismo socialdemócrata o liberal? San José: FLACSO Costa Rica.

Wallerstein, I. (2004). Impensar las ciencias sociales. Los límites de los paradigmas decimonónicos. México: Siglo XXI Editores.

Xirinachs, Y. (2017). Costa Rica a 10 años del CAFTA. Efectos sobre las Exportaciones, la Inversión Extranjera Directa y el Consumo Privado. San José: Proyecto Estado de la Nación; CONARE. 
